\title{
Transcriptome analysis provides new insights into plants responses under phosphate starvation in association with chilling stress
}

\author{
Xiaoning Gao ${ }^{1 \dagger}$, Jinsong Dong ${ }^{2 \dagger}$, Fatemeh Rasouli ${ }^{2}$, Ali Kiani Pouya ${ }^{2}$, Ayesha T. Tahir ${ }^{3 *}$ and Jun Kang ${ }^{{ }^{*}}$
}

\begin{abstract}
Background: Chilling temperature reduces the rate of photosynthesis in plants, which is more pronounced in association with phosphate (Pi) starvation. Previous studies showed that Pi resupply improves recovery of the rate of photosynthesis in plants much better under combination of dual stresses than in non-chilled samples. However, the underlying mechanism remains poorly understood.

Results: In this study, RNA-seq analysis showed the expression level of 41 photosynthetic genes in plant roots increased under phosphate starvation associated with $4^{\circ} \mathrm{C}\left(-\mathrm{P} 4^{\circ} \mathrm{C}\right)$ compared to $-\mathrm{P} 23^{\circ} \mathrm{C}$. Moreover, iron uptake increased significantly in the stem cell niche (SCN) of wild type (WT) roots in -P $4^{\circ} \mathrm{C}$. In contrast, lower iron concentrations were found in $\mathrm{SCN}$ of aluminum activated malate transporter 1 (almt 1 ) and its transcription factor, sensitive to protein rhizotoxicity 1 (stop 1) mutants under $-\mathrm{P} 4{ }^{\circ} \mathrm{C}$. The Fe content examined by ICP-MS analysis in $-\mathrm{P} 4{ }^{\circ} \mathrm{C}$ treated almt 1 was $98.5 \mathrm{ng} / \mathrm{\mu g}$, which was only $17 \%$ of that of seedlings grown under $-\mathrm{P} 23^{\circ} \mathrm{C}$. Average plastid number in almt 1 root cells under $-\mathrm{P} 4^{\circ} \mathrm{C}$ was less than $-\mathrm{P} 23^{\circ} \mathrm{C}$. Furthermore, stop 1 and almt 1 single mutants both exhibited increased primary root elongation than WT under combined stresses. In addition, dark treatment blocked the root elongation phenotype of stop 1 and almt1.
\end{abstract}

Conclusions: Induction of photosynthetic gene expression and increased iron accumulation in roots is required for plant adjustment to chilling in association with phosphate starvation.

Keywords: Phosphate starvation, Chilling stress, STOP1, ALMT1, Fe accumulation

\section{Background}

Phosphorus (P) is one of the macronutrient notably essential for the growth of plants. Plants have to evolve strategies such as efficient use of inorganic phosphate (Pi), the major form of $\mathrm{P}$ available from soil, to overcome the low Pi availability in many agricultural systems [1]. Photosynthesis inhibition under -P conditions is one of

\footnotetext{
*Correspondence: ayesha.tahir@comsats.edu.pk; jun.kang@tju.edu.cn

${ }^{+}$Xiaoning Gao and Jinsong Dong contributed equally to this work.

${ }^{1}$ School of life sciences, Tianjin University, No.92 Weijin Road, Nankai District, 300072 Tianjin, China

${ }^{3}$ Department of Biosciences, COMSATS University Islamabad, Park road,

45550 Islamabad, Pakistan

Full list of author information is available at the end of the article
}

the mechanisms reported to overcome this deficiency. Under -P condition the energy-transducing system is impaired, consequently inhibiting several Calvin cycle enzymatic activities [2, 3]. Deficiency of this macronutrient inhibits triose-P translocation from stroma to cytosol and results in increased production of starch and release of Pi. Thereafter, this Pi is mainly consumed for ATP generation in the light reaction of photosynthesis. However, inhibition of photosynthesis leads to conservation of Pi under its -P condition. Several microarray studies unveiled the down regulation of photosynthetic genes in plants under Pi depletion $[4,5]$.

Chilling stress is also among one of the abiotic stresses responsible for low productivity and limited crop growth

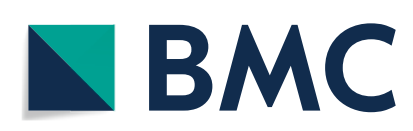

(c) The Author(s) 2022. Open Access This article is licensed under a Creative Commons Attribution 4.0 International License, which permits use, sharing, adaptation, distribution and reproduction in any medium or format, as long as you give appropriate credit to the original author(s) and the source, provide a link to the Creative Commons licence, and indicate if changes were made. The images or other third party material in this article are included in the article's Creative Commons licence, unless indicated otherwise in a credit line to the material. If material is not included in the article's Creative Commons licence and your intended use is not permitted by statutory regulation or exceeds the permitted use, you will need to obtain permission directly from the copyright holder. To view a copy of this licence, visit http://creativecommons.org/licenses/by/4.0/. The Creative Commons Public Domain Dedication waiver (http://creativeco mmons.org/publicdomain/zero/1.0/) applies to the data made available in this article, unless otherwise stated in a credit line to the data. 
[6]. The efficiency of photosynthetic electron transport in plants is reduced by low temperatures and in combination with high light treatment could even lead to photoinhibition by implication of photosystem I (PSI) instead of PSII $[7,8]$. The PS I system is the major storage place of plant iron $(\mathrm{Fe})$, an important micronutrient for various plant functions. Hence, alterations in system functioning can lead to change in homeostasis of Fe as well as oxidation-reduction reactions controlled by iron-sulfur (Fe-S) centers (Fe-Sx, FeSA, and FeSB) in the PS I system [9].

When plants are grown in transparent petri dishes under Pi deficient (-P) condition, primary root elongation will be inhibited as the accumulation of hydroxyl radicals caused by Fe redox cycle in the root apoplast [10]. Plants mostly accumulate high Fe levels in the maturation zone of roots, while in stem cell niche (SCN) and cortex of roots the level is usually very low $[5,11]$. The Fe accumulation pattern for plants under Pi deficiency in association with chilling is largely unknown.

In Arabidopsis thaliana, several proteins play pivotal roles in Fe accumulation. During Pi starvation, interaction between LPR (Low Phosphate Root) and PDR2 (Phosphate Deficiency Response 2) facilitate cell-specific apoplastic Fe and callose deposition in both the meristem and elongation zone of primary roots [12, 13]. The STOP1 (Sensitive to Protein Rhizotoxicity) transcription factor regulates the expression of the plasma membranelocalized Aluminum Activated Malate Transporter 1 (ALMT1). A previous study showed that phosphate depletion activates STOP1-ALMT1, which rapidly results in inhibition of root cell elongation [14]. The LPR1PDR2 module interacts with an unknown pathway parallel to STOP1-ALMT1 and inhibits cell division in SCN by a similar mechanism involving Fe accumulation [12, 15]. Implication of STOP1 and ALMT1 under Pi, aluminium and Fe stress is known, their entanglement under a combination of -P and chilling stress has not yet been reported.

In study presented here, we showed that the genes controlling the Fe homeostasis in root $\mathrm{SCN}$ are involved in the recovery of photosynthesis rate for $-\mathrm{P} 4{ }^{\circ} \mathrm{C}$ treated plants. Fe accumulation pattern in stop1,almt1 and lpr1lpr2 mutants, RNA-seq and qPCR data of photosynthesis related genes and TEM observations for starch granules and chloroplast helped us to unravel the role of STOP1 and ALMT1 under action of dual stress.

\section{Results}

RNA-seq analyses of the root transcriptome under chilling stress and Pi starvation

To elucidate the molecular mechanisms under combined action of cold stress and Pi starvation (-P) in plant roots, a comparative RNA-seq analysis of root transcriptome was performed. cDNA libraries were constructed from the roots of 7-day-old WT seedlings using the total RNA, which were divided into four groups according to the growth condition to which they were subjected: $+\mathrm{P}$ medium, $-\mathrm{P}$ medium, $23^{\circ} \mathrm{C}$, or transferred to $4{ }^{\circ} \mathrm{C}$ for $24 \mathrm{~h}$. Using an Illumina HiSeq sequencer, low quality reads as well as those that aligned to either rRNA or tRNA were removed. Total of 247,236,020 reads were selected for additional analysis (Table S1). The raw data of Illumina reads is available at the NCBI Sequence Read Archive browser (http://ncbi. nlm.nih.gov/sra, accession no. PRJNA609588). For each sample, $\sim 95.86 \%$ of reads mapped to the Arabidopsis TAIR10 reference genome. Of these mapped reads, $\sim 93.57 \%$ were aligned to unique genes without ambiguity. RNA expression profiles gross comparisons against $+\mathrm{P} 23^{\circ} \mathrm{C}$ WT roots are shown in Fig. 1 A-D.

First, we compared the transcriptome of the roots of WT seedlings under $-\mathrm{P} 23{ }^{\circ} \mathrm{C}$ and $+\mathrm{P} 23^{\circ} \mathrm{C}$. In $-\mathrm{P} 23^{\circ} \mathrm{C}$ wild type (WT) seedlings, expression was induced for 616 genes and repressed for 906 genes (Fig. 1 A, B and C). Five phosphate starvation induced (PSI) marker genes (At4, IPS1, PHT1;4, SPX1, and RNS1) were found among the induced gene category, as also previously reported by [16]. The fold-change of these five psi genes was $4.9,8.5,3.2,4.3$, and 5.5 , respectively. The induction of these five psi genes in Pi-deficient root tips confirmed that the experimental conditions for RNA-seq analysis were appropriate. In -P WT, we also found upregulation of many other known PSI genes such as the Pi transporters Pht1;3, Pht1;7 and Pht1;9, purple acid phosphatase 23 (AtPAP23) [17, 18]; the Pi-signaling components SPX3, MIR399B, MIR399C, and MIR399D [19, 20]; copper transport protein family, LSU2, an indication of a cross-talk between different nutrients for their uptake and metabolism [21, 22]. Enhanced expression of BCAT4, MAM1, IPMI1 and IPMI2 [23-25] suggested elevated biosynthesis of glucosinolates and branched-chain amino acids (Table S2).

In the category of down-regulated genes mainly two functional groups were enriched in $-\mathrm{P} 23{ }^{\circ} \mathrm{C}$ seedlings. One group was dominated by transcription factors (total number: 58) whereas a second group was comprised of photosynthesis-related (PR) genes (total number: 75) (Fig. 1D, Table S3). In the second group we found 18 genes encoding subunits of photosystem I, 17 chlorophyll-binding proteins, 13 genes encoding enzymes involved in the Calvin cycle and 27 genes encoding subunits of PS II (Table S4). None of these photosynthetic genes were up-regulated in $-\mathrm{P} 23{ }^{\circ} \mathrm{C}$ roots, and the expression level of $\sim 70 \%$ of these genes was two times higher in $+\mathrm{P} 23^{\circ} \mathrm{C}$. 


\section{A Up-regulated genes}

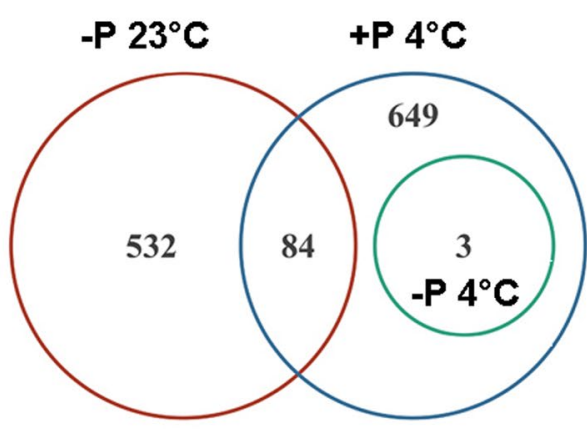

B

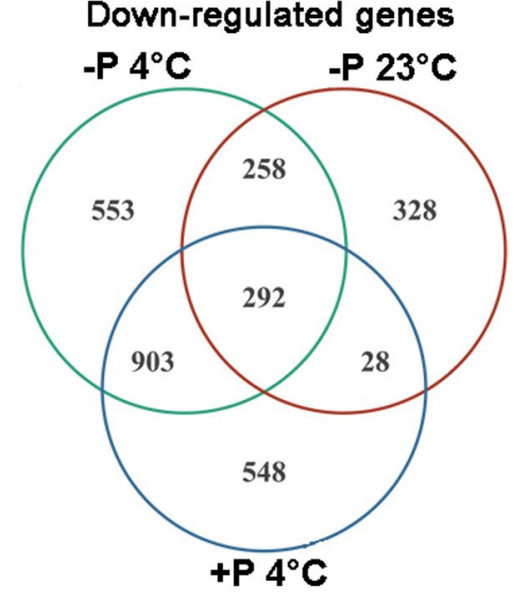

C

All differentially expressed transcripts

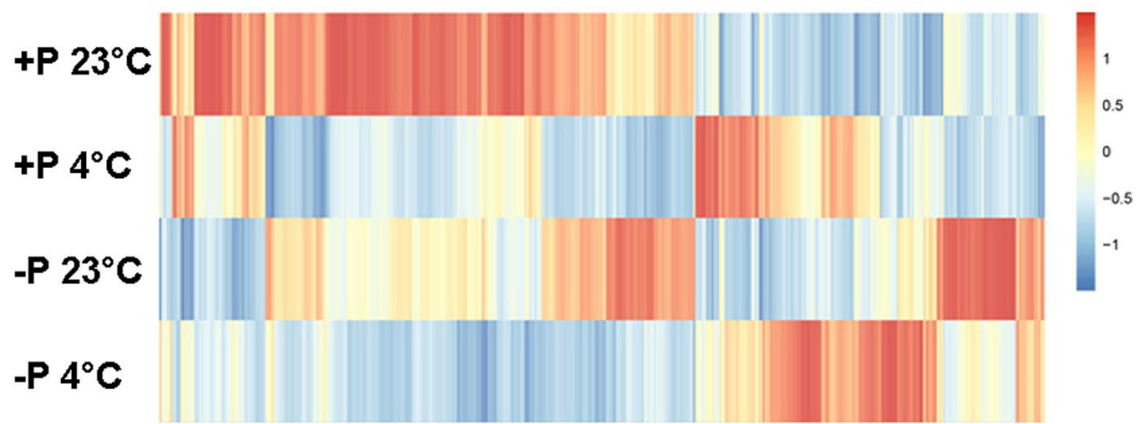

D

Transcripts encoding transcription factors

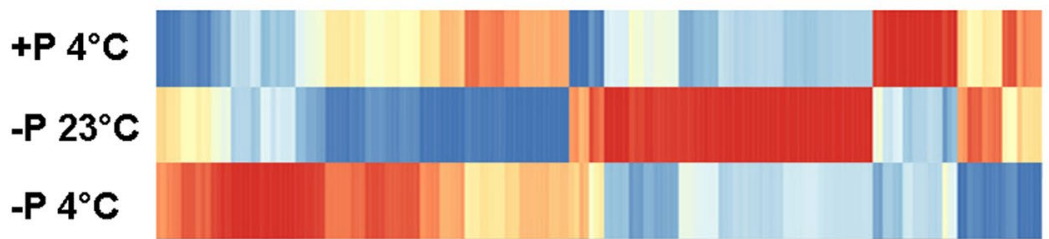

Fig. 1 Differentially expressed transcripts in the roots of 7-day-old seedlings grown under $23^{\circ} \mathrm{C} / 4^{\circ} \mathrm{C}$ in association with $+\mathrm{P} /-\mathrm{P}$ condition. A Venn plot of up regulated genes. $\mathbf{B}$ Venn plot of down-regulated genes by Pi deficiency and $4^{\circ} \mathrm{C}$. $\mathbf{C}$ Expression patterns of all transcripts that were differentially expressed in our analysis. D Expression patterns of differentially expressed transcription factors

The transcriptome of $+\mathrm{P} 4{ }^{\circ} \mathrm{C}$ was then compared to $+\mathrm{P} 23{ }^{\circ} \mathrm{C}$. In $+\mathrm{P} 4{ }^{\circ} \mathrm{C}$, 736 genes were upregulated while 1771 genes were downregulated (Fig. $1 \mathrm{~A}, \mathrm{~B}$ and $\mathrm{C}$, Table S5). 92 of 220 transcription factors were up-regulated and 128 were down-regulated (Fig. 1D and Table S6). The largest increase in induction among transcription factors (4.9-fold increase) in $+\mathrm{P} 4{ }^{\circ} \mathrm{C}$ was found for PRR9 (At2g46790). PRR7 (AT5G02810) and PRR9 are partially redundant essential components of a temperature-sensitive circadian system [26]. CCA1 (At2g46830) encodes a transcriptional repressor that performs overlapping functions with $L H Y$ (At1g01060) in a regulatory feedback loop that is closely associated with the circadian oscillator of Arabidopsis. CCA1 and $L H Y$ exerted a positive effect on PRR9 [27]. Photosynthesis-related genes were mostly down-regulated (52 out of 54), including 9 genes encoding chlorophyll-binding proteins, 15 genes encoding enzymes involved in the Calvin cycle, 13 genes encoding subunits of photosystem I, 17 genes encoding subunits of photosystem II (Table S7).

Finally, the transcriptomes of seedlings grown on -P $4{ }^{\circ} \mathrm{C}$ and -P $23{ }^{\circ} \mathrm{C}$ media were compared to determine the effects of chilling stress on gene expression profiles in plants under phosphate starvation. 996 genes 
were up-regulated in $-\mathrm{P} 4{ }^{\circ} \mathrm{C}$ whereas 1676 genes were down-regulated (Fig. 1 A, B and C, Table S8). Genes that belonged to transcription factors and photosynthetic regulation were the most enriched categories. Among the transcription factors, expression of 72 genes was increased and that of 65 genes was decreased in $-\mathrm{P} 4{ }^{\circ} \mathrm{C}$ relative to $-\mathrm{P} 23{ }^{\circ} \mathrm{C}$. The largest increase in induction among transcription factors (7.8-fold increase) was found for $C B F 3$, which encodes a member of the DREB subfamily A-1 of ERF/AP2 transcription factor family [28] (Table S9). Activation of CBF3 triggers feedback on temperature perception by suppressing the premature coldacclimation at standard temperature. Three zinc finger (B-box type) family proteins (At4g27310, At5g54470, and At3g21890) [29] were also expressed at high level, with inductions of 4.8, 4.2, and 4.2 fold, respectively. Among 48 differentially expressed photosynthesis-related genes, expression of 41 photosynthetic genes was elevated in -P $4{ }^{\circ} \mathrm{C}$ compared to $-\mathrm{P} 23^{\circ} \mathrm{C}$. Highest fold changes among genes involved in photosynthesis were for three ribulose bisphosphate carboxylase small chains $2 B, 3 B$, and $1 B$ [30] with expression levels of 11.7, 8.7, and 6.4, respectively. Elevated expression of four ferritins (HY2, ATFRO5, FD2, and GLU1) [31-33], indicated that the Fe homeostasis in roots might be enhanced after $4{ }^{\circ} \mathrm{C}$ treatment under -P stress. Several important components earlier reported to be involved in the photosystem including AGT1, PPL1, CAB3, PIF1, GAPA-2, and PSAH2 [32, 34-38], were also highly induced (Table S10), indicating that the ability for photosynthesis has been enhanced in plants at $4{ }^{\circ} \mathrm{C}$ compared with $23{ }^{\circ} \mathrm{C}$ under -P stress.

\section{Verification of photosynthesis-related and marker gene mRNA expression level}

To confirm the mRNA expression of the marker genes in response to Pi starvation and cold stress in roots, qPCR was performed using roots of the 7-day-old seedlings. Eight photosynthesis-related or marker genes were analyzed for their expression in WT grown under different $\mathrm{Pi}$ and temperature conditions. These eight genes encode: $A G T 1$, a peroxisomal photorespiratory enzyme that catalyzes transamination reactions with multiple substrates and which is involved in photorespiration; $R B C S 1 B$, a member of the rubisco small subunit (RBCS) multigene family; IPS1, a non-coding transcript; KIN1, an anti-freeze protein ; ERF109, a member of the ethylene response factor (ERF) subfamily B-3 of the ERF/ AP2 transcription factor family; MAPKKK19, a member of the MEKK subfamily; PIN5, a functional auxin transporter that is required for auxin-mediated development. PIN5 does not have a direct role in cell-to-cell transport but regulates intracellular auxin homeostasis and metabolism; and COR15A, whose constitutive expression increases freezing tolerance in protoplasts in vitro and chloroplasts in vivo. As expected, the expressions of IPS1, KIN1, MAPKKK19, PIN5 and COR15A were enhanced by Pi starvation or cold stress (Figure S1); interestingly, the induction level of $A G T 1$ and $R B C S 1 B$ was much higher in $-\mathrm{P} 4{ }^{\circ} \mathrm{C}$ than in $-\mathrm{P} 23{ }^{\circ} \mathrm{C}$ and $+\mathrm{P} 4{ }^{\circ} \mathrm{C}$, and even 3-4 times higher than that in $+\mathrm{P} 23^{\circ} \mathrm{C}$.

\section{stop1 and almt 1 accumulated less $\mathrm{Fe}^{3+}$ than WT in roots under chilling in association with Pi starvation stress}

Previous studies showed that iron-sulfur (Fe-S) compounds (ferritin) played a significant role in the PS I process. These proteins are pivotal centers for Fe storage in plants. To identify whether the increased expression level of ferritins in $-\mathrm{P} 4{ }^{\circ} \mathrm{C}$ plants was attributable to $\mathrm{Fe}$ absorption, the Fe accumulation pattern was identified in Arabidopsis roots under four treatment conditions. Seeds were sown on $+\mathrm{P}$ and $-\mathrm{P}$ media at 4 and $23{ }^{\circ} \mathrm{C}$. Perls/ $\mathrm{DAB}$ (diaminobenzidine) staining method which stains $\mathrm{Fe}^{2+}$ as well as $\mathrm{Fe}^{3+}$. Clearly, the WT seedlings grown on $+\mathrm{P} 23{ }^{\circ} \mathrm{C}$ and $+\mathrm{P} 4{ }^{\circ} \mathrm{C}$ showed dark brown Fe staining (Fig. 2). There was no significant difference between the two treatments. For seedlings grown on $-\mathrm{P} 23{ }^{\circ} \mathrm{C}$, $\mathrm{Fe}^{3+}$ accumulation in the $\mathrm{SCN}$, cortex, and root apex was strongly decreased, instead, darker brown staining in -P $4{ }^{\circ} \mathrm{C}$ treated WT roots was much sharper compared to that of $-\mathrm{P} 23^{\circ} \mathrm{C}$ plants (Fig. 2). This result demonstrated an increased $\mathrm{Fe}$ accumulation in root tips under $-\mathrm{P} 4{ }^{\circ} \mathrm{C}$ compared with $-\mathrm{P} 23^{\circ} \mathrm{C}$, indicating the impact of chilling stress on Fe homeostasis in root SCN.

Seeds of stop1, almt1 and lpr1lpr2 were also sown on both $+\mathrm{P}$ and $-\mathrm{P}$ media as they have been reported to paly pivotal role in Fe homeostasis. Results showed that, $\mathrm{Fe}$ accumulation in roots of all mutants showed almost no difference between $23{ }^{\circ} \mathrm{C}$ and $4{ }^{\circ} \mathrm{C}$ under $+\mathrm{P}$ condition. With -P treatment, Fe deposition in the quiescent center (QC) of lpr1lpr2 in at $4{ }^{\circ} \mathrm{C}$ increased and was notably stronger in two or three cells than at $23^{\circ} \mathrm{C}$ (Fig. 2). However, in stop 1 and almt1 mutants, the Fe distribution in $\mathrm{SCN}$ was lower in $-\mathrm{P} 4{ }^{\circ} \mathrm{C}$ compared to $-\mathrm{P} 23^{\circ} \mathrm{C}$.

Quantitative analysis indicated that the total Fe content was about three times higher in $-\mathrm{P} 23^{\circ} \mathrm{C}$ seedlings of WT compared to that for $+\mathrm{P} 23{ }^{\circ} \mathrm{C}$ (Fig. 3). $-\mathrm{P} 4{ }^{\circ} \mathrm{C}$ treated WT and lpr1lpr2 Fe contents were $448.5 \mathrm{ng} / \mu \mathrm{g}$ and $489.5 \mathrm{ng} / \mu \mathrm{g}$ respectively. However, the Fe content in $-\mathrm{P} 4{ }^{\circ} \mathrm{C}$ treated $a l m t 1$ was only $98.5 \mathrm{ng} / \mu \mathrm{g}$. In $-\mathrm{P} 4{ }^{\circ} \mathrm{C}$ treated stop1, Fe content was $373.5 \mathrm{ng} / \mu \mathrm{g}$ (Fig. 3). These results suggested that the enhanced Fe accumulation in plant root tips under $-\mathrm{P} 4{ }^{\circ} \mathrm{C}$ might be caused by ALMT1 and STOP1. 


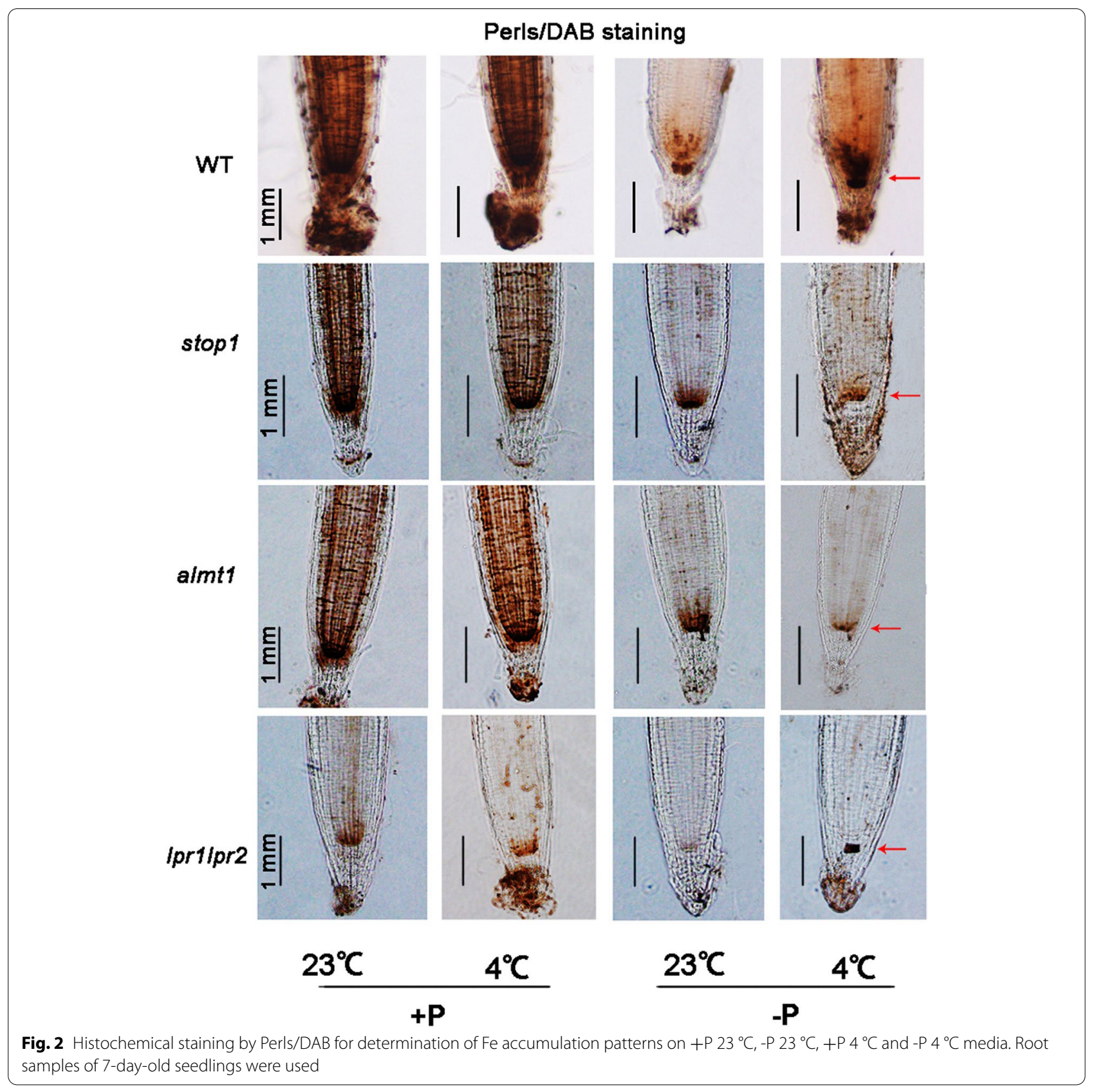

\section{stop1 and almt1 mutations lead to suppressed PR phenotypes under $-\mathrm{P} 4^{\circ} \mathrm{C}$}

To ascertain whether the relatively increased expression of photosynthetic genes actually impact the photosynthesis-related phenotypes in plants, the chloroplast development in shoot apical meristems was examined via transmission electron microscopy (TEM). The results are shown in Fig. 4. There were some similar phenotypes among WT, almt1 and stop1. For instance, the cell wall was very firm in all types of plants under
$+\mathrm{P} 23{ }^{\circ} \mathrm{C}$ treatment, and every cell contained $\sim 4$ chloroplasts with well-developed grana stacks, with the average number of starch granules in each chloroplast was approximately 0.4 . Under $+\mathrm{P} 4{ }^{\circ} \mathrm{C}$ treatment, cell walls looked looser than those under $+\mathrm{P} 23{ }^{\circ} \mathrm{C}$ treatment. An average of four chloroplasts were found per cell with less well developing grana stacks than in the $+\mathrm{P} 23{ }^{\circ} \mathrm{C}$ treatment. The average number of starch granules increased to $\sim 2.5$ per chloroplast. With the $-\mathrm{P} 23{ }^{\circ} \mathrm{C}$ treatment we obtained an average of 4.2 


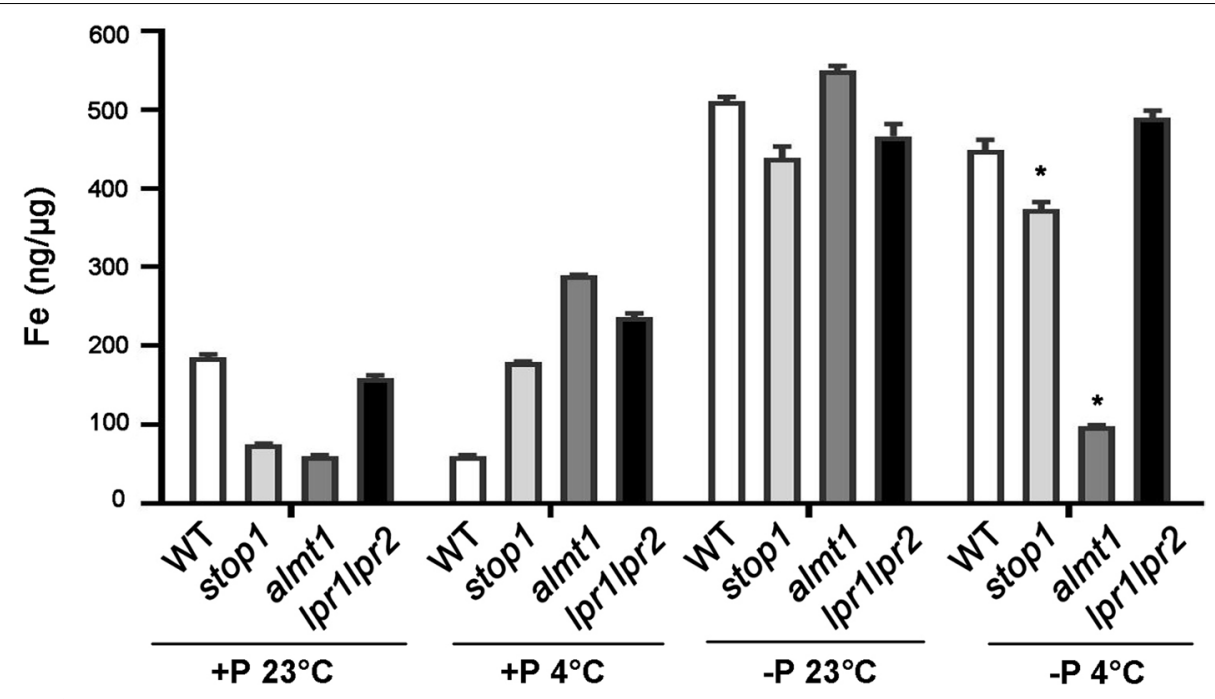

Fig. 3 Quantification of Fe content in WT, stop 1, almt1 and lprilpr2 seedlings grown on $+\mathrm{P} 23^{\circ} \mathrm{C},-\mathrm{P} 23^{\circ} \mathrm{C},+\mathrm{P} 4{ }^{\circ} \mathrm{C}$ and $-\mathrm{P} 4^{\circ} \mathrm{C}$ media. 10 -day-old seedlings were used to take the roots for assay. The values are means $\pm S D$ of three biological replicates. * $(t$-test, $P<0.05)$

chloroplasts per cell with well-developed grana stacks, though lacking the starch granules.

In addition to the number of chloroplasts, the accumulation pattern of starch granules in almt1 and stop 1 under $-\mathrm{P} 4{ }^{\circ} \mathrm{C}$ were much different from those in WT. The average number of chloroplasts in WT was 7.2 per cell, and all contained well developed starch granules with an average number of 4.0 per chloroplast (Fig. 4). However, there were only 5.9 and 6.2 chloroplasts per cell in almt 1 and stop 1 with poorly developed starch granules, 2.9 and 3.0 respectively. In addition, the cell wall of WT was looser than those of almt 1 and stop 1 . The chloroplasts in the two mutants were arranged more tightly compared to their arrangement in WT (Fig. 4).

Patterns of chlorophyll auto-florescence of 10-day-old seedling roots were also analyzed. Compared to WT under $-\mathrm{P} 4{ }^{\circ} \mathrm{C}$, the signal intensity in almt 1 and stop 1 mutants could hardly be detected (Fig. 5), which indicates the poor root plastid development under dual stress. These findings indicated that mutation of almt1 and stop 1 suppressed the photosynthetic reaction induced by $-\mathrm{P} 4{ }^{\circ} \mathrm{C}$.

\section{stop 1 and almt 1 showed promoted primary root elongation under phosphate starvation associated with chilling stresses}

Over-accumulation of Fe always leads to inhibition of primary root elongation. In contrast, lower concentration of Fe deposit leads to insensitive root elongation phenotype under phosphate starvation stress [12]. To detect the primary root elongation condition under combined stresses, the WT, stop1, almt1 and lpr1lpr2 seeds were planted in $+\mathrm{P}$ and $-\mathrm{P}$ media (both at two temperatures 4 and $23{ }^{\circ} \mathrm{C}$ ). Results showed that primary root elongation was inhibited in stop 1 and almt 1 under $+\mathrm{P}$ associated with $23{ }^{\circ} \mathrm{C}\left(+\mathrm{P} 23{ }^{\circ} \mathrm{C}\right)$ treatment. Under $-\mathrm{P} 23{ }^{\circ} \mathrm{C}$ and $+\mathrm{P} 4{ }^{\circ} \mathrm{C}$, the difference of primary root elongation among WT and stop 1 and almt 1 was not obvious (Fig. $6 \mathrm{~A}$ ). However, the length of primary root was longer in stop1 and almt1 compared with WT under -P $4{ }^{\circ} \mathrm{C}$ condition (Fig. 6 A). Quantitative data revealed that the difference of primary root length among WT, stop1 and almt1 was significant (Fig. 6B).

Fig. 4 Shoot apical meristem chloroplast and starch grain contents of WT, almt1 and stop 1 seedlings grown on $+\mathrm{P} 23^{\circ} \mathrm{C},-\mathrm{P} 23^{\circ} \mathrm{C},+\mathrm{P} 4^{\circ} \mathrm{C}$ and or $-\mathrm{P}$ $4{ }^{\circ} \mathrm{C}$ conditions. Samples were analyzed at $10 \mathrm{DAG}$, by transmission electron microscopy (TEM). A TEM micrographs of chloroplast in one cell; $\mathbf{B}$ the accumulation of starch grains in one chloroplast; $\mathbf{C}$ number of chloroplast per cell and starch grains per chloroplast. In (B) and (C), values are means of 30 cells \pm SD. Bars $=1 \mu \mathrm{m}$ 


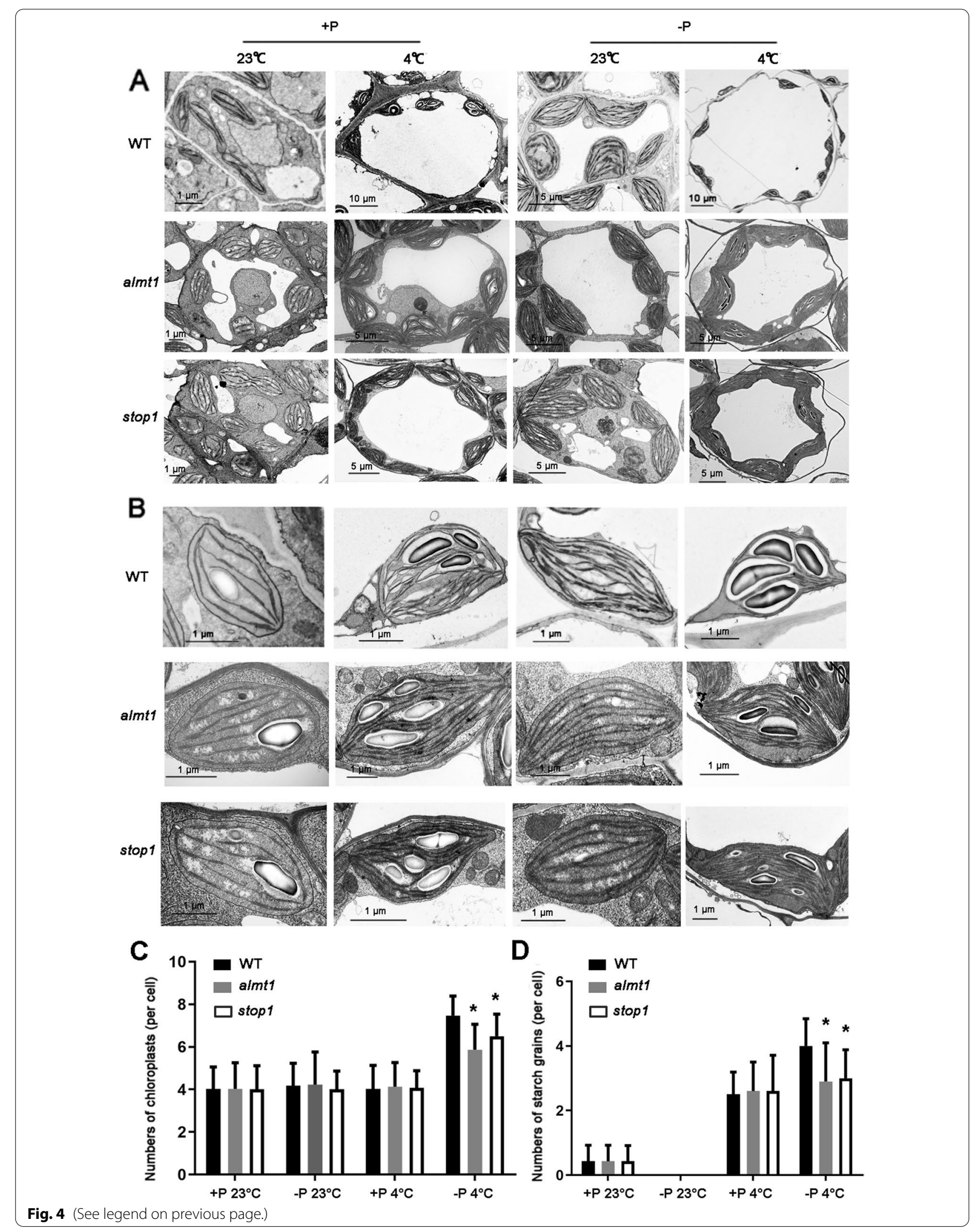




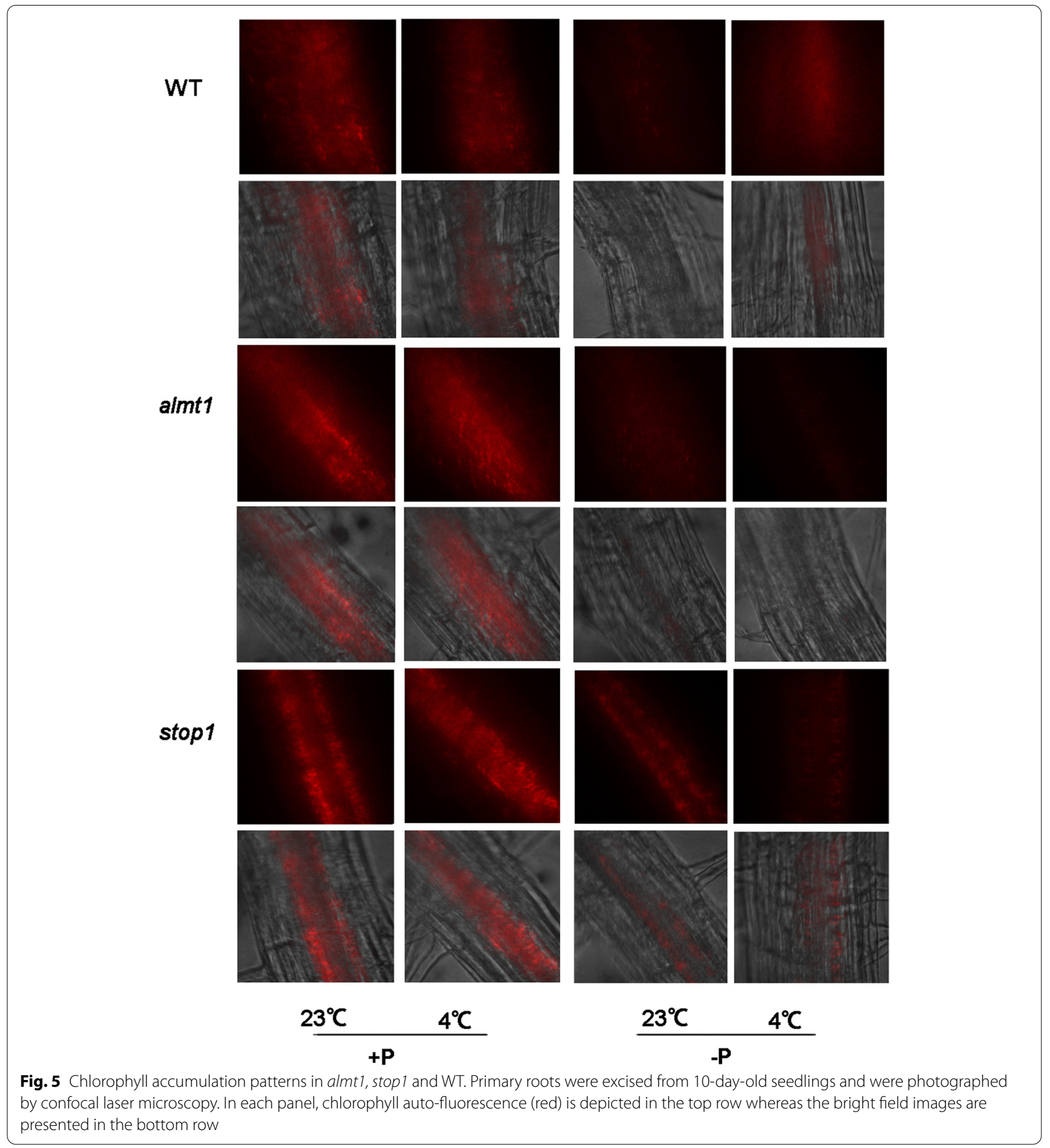

\section{Dark treatment blocked the primary root elongation} phenotype of almt 1 and stop 1 under $-\mathrm{P} 4{ }^{\circ} \mathrm{C}$

To further investigate the primary root elongation when photosynthesis was inhibited, the dark treatment with combined stresses was conducted. The WT, stop 1, almt1 and lpr1lpr2 seeds were planted in $+\mathrm{P}$ and
-P media and cultured under 4 and $23{ }^{\circ} \mathrm{C}$, respectively (Fig. 7 A). It was easy to find that there was no obvious difference in primary root elongation of the WT, stop1 and almt1 under four conditions. Quantitative analysis of primary root length further revealed that the difference among WT, stop1, almt1 was not significant 

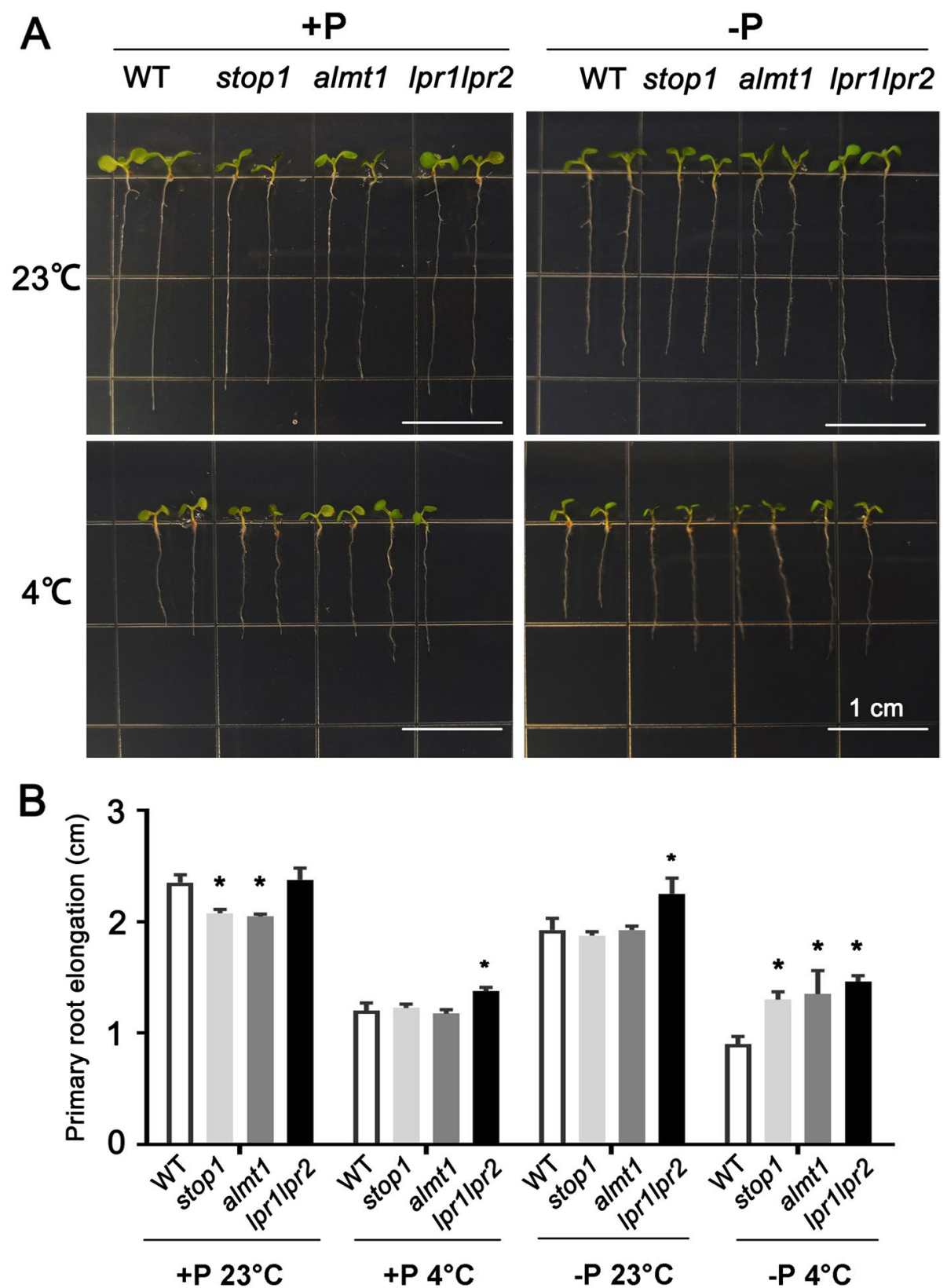

Fig. 6 Primary root elongation under $+\mathrm{P} 23^{\circ} \mathrm{C},-\mathrm{P} 23^{\circ} \mathrm{C},+\mathrm{P} 4{ }^{\circ} \mathrm{C}$ and $-\mathrm{P} 4{ }^{\circ} \mathrm{C}$ conditions. (A) Phenotype of 7-day-old WT, stop 1, almt1 and lpr $1 / p r 2$ seedlings; (B) Quantification of primary root elongation of plants. The values are means $\pm S D$ of ten biological replicates. ${ }^{*}(t$-test, $P<0.05)$

(Fig. 7B). Clearly, dark treatment blocked the function of almt 1 and stop 1 in Fe homeostasis under $-\mathrm{P} 4{ }^{\circ} \mathrm{C}$.

\section{Discussion}

Reduced photosynthesis rate in plants under Pi starvation or cold stress has been observed more than 20 years ago $[7,16]$. When low-Pi plants are resupplied with $\mathrm{Pi}$, the rate of photosynthesis and stomatal conductance in chilled tomato plants recovered much better (approximately twice as well) than in non-chilled samples. Although plants over-accumulate Fe under Pi starvation stress, little Fe was found accumulated in the SCN and cortex of roots [11]. This study provided first evidence that Fe storage was enhanced in SCN of WT, especially in QC, under -P associated with cold stress. Consequently, increased Fe accumulation mediated by ALMT1 and STOP1 led to the inhibition of primary root 

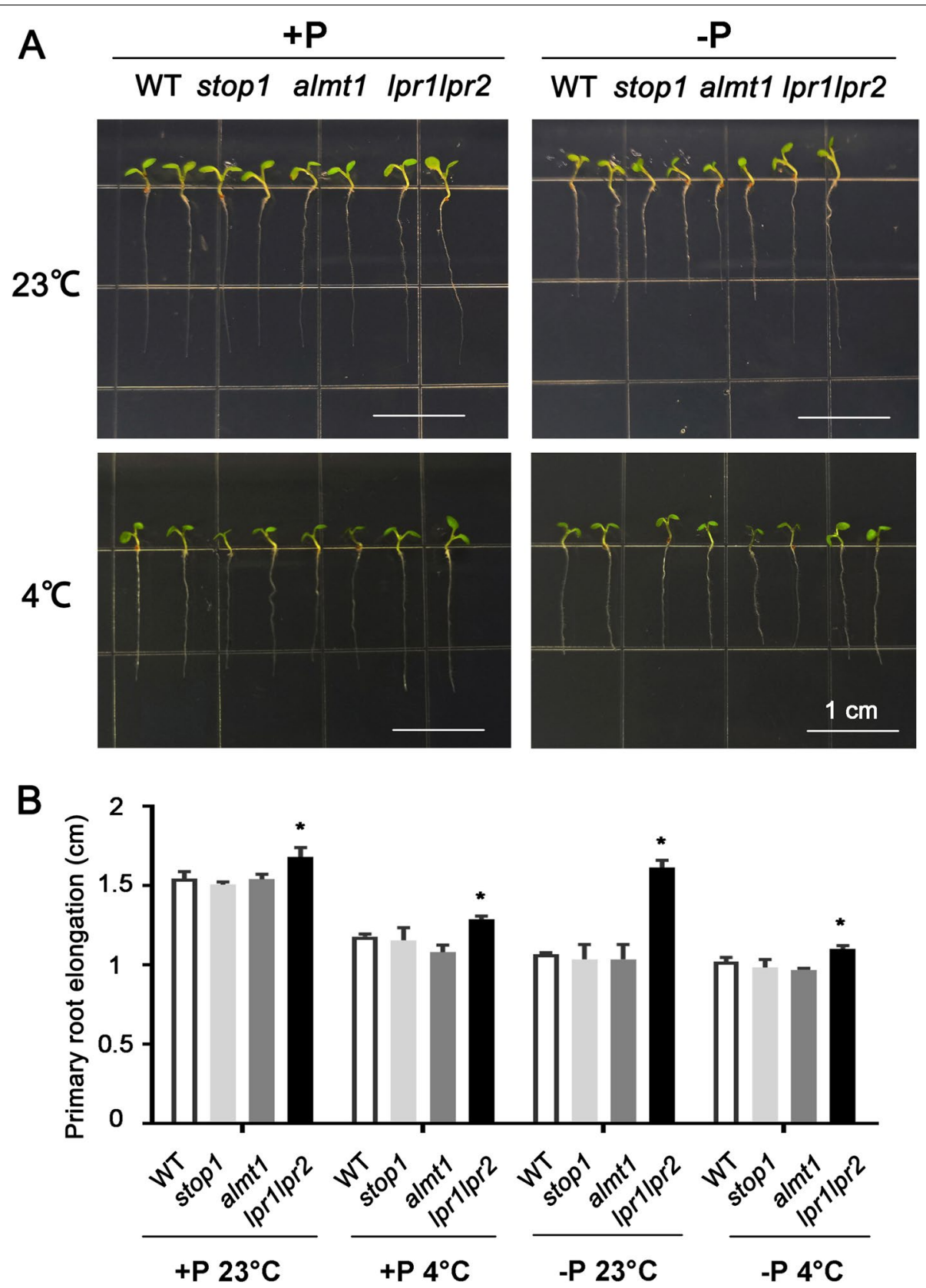

Fig. 7 Primary root elongation with dark treatment under $+\mathrm{P} 23^{\circ} \mathrm{C},-\mathrm{P} 23^{\circ} \mathrm{C},+\mathrm{P} 4^{\circ} \mathrm{C}$ and $-\mathrm{P} 4^{\circ} \mathrm{C}$ conditions. (A) Phenotype of 7-day-old $W T$, stop 1,almt1 and Ipr1/pr2 seedlings; (B) Quantification of primary rootelongation of plants. The values are means \pm SD of ten biological replicates. $*(t$-test, $P<0.05)$

elongation and aided for plant adjustment to combinations of chilling stress and phosphate deficiency.

Fe is a pivotal macronutrient for PS I process, as it is important for the synthesis of Fe-S proteins working in PS I reaction center [9]. Shortage of Fe would lead to the decreased efficiency of light reaction processes, which results in the inhibition of ATP synthesis, reducing $\mathrm{CO}_{2}$ immobilization and reduced starch grain accumulation during dark reaction [39]. On the other hand, over-accumulation of $\mathrm{Fe}$ in roots leads to the inhibited primary root elongation as the high level of reactive oxygen species (ROS) result in an increased callose deposition in cell walls and plasmodesmata [11]. In almt1 and stop 1 mutants, the Perls/DAB staining of roots under $-\mathrm{P} 4{ }^{\circ} \mathrm{C}$ was much lighter than for those under $-\mathrm{P} 23^{\circ} \mathrm{C}$ (Fig. 3). Clearly, mutation of almt1 and stop 1 inhibited the $\mathrm{Fe}$ 
accumulation for plant grown under $-\mathrm{P} 4{ }^{\circ} \mathrm{C}$. However, there was still some Fe accumulation in $\mathrm{SCN}$ of almt1 and stop1. Two reasons might be the cause of this result: one is the $4{ }^{\circ} \mathrm{C}$ treatment for $24 \mathrm{~h}$ was not long enough for the remaining Fe consumption in almt1 and stop 1; the other is that some other Fe translocation proteins also involved in basic $\mathrm{Fe}$ absorption during $-\mathrm{P} 4{ }^{\circ} \mathrm{C}$ treatment, e.g. LPR1 and LPR2. Fe transporters involved in the maintenance of $\mathrm{Fe}$ homeostasis under $-\mathrm{P} 4{ }^{\circ} \mathrm{C}$ treatment needs further experimental validation and verification.

The RNA-Seq analysis was also used to understand the molecular basis of cross talk between Fe absorption, $-\mathrm{P}$ and chilling stress. We particularly focused on the -P $4{ }^{\circ} \mathrm{C}$ vs. - $\mathrm{P} 23{ }^{\circ} \mathrm{C}$ group. The largest increase in induction among transcription factors in $-\mathrm{P} 4{ }^{\circ} \mathrm{C}$ was 7.8 -fold (CBF3). The expression level of the same subfamily member, $C B F 2$, was also induced. Recently $C B F$ (C-repeat binding factor) pathway has been reported to play key role in plant cold acclimation, a process to increase freezing tolerance to low but non-freezing temperatures in certain plants [40]. This suggests that phosphate deficiency increases the tolerance against chilling stress $\left(4{ }^{\circ} \mathrm{C}\right)$ to a certain extent. Combined with the increased Fe content in root SCN, we suggest that induced freezing tolerance might be caused by the increased ratio of photosynthesis under $-\mathrm{P} 4{ }^{\circ} \mathrm{C}$. Furthermore, three zinc finger (B-box type) family proteins $B B X 28, B B X 29$, and $B B X 31$ were also induced. $B B X 28$ negatively regulates the photomorphogenic development, by interfering the binding of the transcription factor $H Y 5$ to its target gene promoters. The function of $B B X 29$ and $B B X 31$ was not clear before. Our results provided evidence that $B B X 29$ and $B B X 31$ might be involved in the same pathway along with $B B X 28$, for in the inhibition of photomorphogenic development under -P $4{ }^{\circ} \mathrm{C}$ [41]. As photomorphogenic development requires a large amount of $\mathrm{Fe}$ and $\mathrm{Pi}$ to synthesize new proteins and nucleic acids, inhibition of this process was considered to be an active protection regulation for current survival.

In the $-\mathrm{P} 4{ }^{\circ} \mathrm{C}$ vs. $-\mathrm{P} 23{ }^{\circ} \mathrm{C}$ analysis, genes of Rubisco small subunit multigene family (RBCS $2 B, R B C S 3 B$, and $R B C S 1 B$ ) were the most induced genes among the photosynthesis related genes (Table S10). Their function is to produce a sufficient Rubisco content to maintain the photosynthetic capacity of leaves [30]. It is likely that these enhanced photosynthetic genes and the inhibited photomorphogenic development reached a dynamic balance for plant tolerance to dual-stress treatments. Moreover, four ferritin expression levels HY2 [42], ATFRO5 [31], FD2 [33] and GLU1 [43] were up-regulated, suggesting that Fe homeostasis in roots has been enhanced after -P $4{ }^{\circ} \mathrm{C}$ treatment.
Low temperatures disrupt plant cell walls and loosen cell wall structure compared to control, especially in association with -P treatment (Fig. 4). However, the number of chloroplasts in shoot apical meristems was higher in $-\mathrm{P} 4{ }^{\circ} \mathrm{C}$ than in $+\mathrm{P} 23^{\circ} \mathrm{C},-\mathrm{P} 23^{\circ} \mathrm{C}$, and $+\mathrm{P} 4{ }^{\circ} \mathrm{C}$ in WT, almt1 and stop 1 , and was mirrored in the accumulation of starch granules. It is considered that lack of Fe inhibits the efficiency of PS I and low Pi supply limits the ATP synthesis, followed by the decrease in dark reaction ratio.

Dark treatment brings the inhibition of photosynthesis. And it was considered to further suppress the Fe deposition in plant roots. This work provides evidence that the differences in primary root elongation among WT, stop 1 and almt1 was conducted by light (Fig. 7). Light treatment promotes the photosynthesis process, which leads to Fe accumulation, and finally caused the primary root inhibition. Though most plant roots are under the ground, yet, for aquatic plants studies with light subjected roots are of great importance.

\section{Conclusions}

The findings of this study provide some new insights to understand the essential roles of ALMT1 and STOP1 in regulating primary root elongation by promoting iron accumulation in root stem cell niche to maintain photosynthesis during $-\mathrm{P}$ associated with cold stress. More work needs to be carried out to unravel the complicated molecular network involved in regulation of Fe homeostasis and photosynthesis under combined action of dual stress.

\section{Methods}

\section{Plant materials and growth media}

All the Arabidopsis material used in this study is of the Columbia- 0 background. The T-DNA insertion lines for almt1 (SALK_009629C), stop1 (SALK_114108), lpr1-1(SALK_016297) and lpr2-1(SALK_091930) were obtained from the Arabidopsis Biological Resource Center (https://abrc.osu.edu/). The lpr1-1lpr2-1 double mutants were generated by crossing lpr1-1 to lpr2-1. Homozygous lines were verified by PCR using specific LP and RP primers: stop1 (SALK_114108) LP TTC ATTGGTGAGAACGACTCC, stop1 (SALK_114108) RP ATCTTCTTGTTGGTCGTGGTG, almt1 (SALK_009629C) LP GAAACACTGGTGATGTCGAT, almt1 (SALK_009629C) RP GTGTTGATTATATGA TACGA, lpr1-1 (SALK_016297) LP CTCATCGCC AGTAGGTAGCTG, lpr1-1 (SALK_016297) RP ACT CATGGGTGTGAACCAAAG, lpr2-1 (SALK_091930) LP CATAGCCTGGCTCTTGAGTTG, lpr2-1 (SALK_091930) RP GTCATAGCTCAGTCGAATCGC, 
LBb 1.3 (T-DNA primer for SALK lines) BP ATTTTG CCGATTTCGGAAC.

The medium $+\mathrm{P}$ was half-strength $\mathrm{MS}$ medium, which has agar $1.2 \%(\mathrm{w} / \mathrm{v})$ and sucrose $1 \%(\mathrm{w} / \mathrm{v})$. $\mathrm{KH}_{2} \mathrm{PO}_{4}$ used for $+\mathrm{P}$ medium was replaced with $\mathrm{K}_{2} \mathrm{SO}_{4}$ for preparation of -P medium. Seeds were sterilized, thoroughly washed in sterile-distilled water to remove bleach and stratified at $4{ }^{\circ} \mathrm{C}$ for $48 \mathrm{~h}$. For germination and further growth, seeds were shifted to media plates and kept in a growth room at $23{ }^{\circ} \mathrm{C}$ for $16 \mathrm{~h} / 8 \mathrm{~h}$ day night light conditions. After 6 days, half of the seedlings were kept at $4{ }^{\circ} \mathrm{C}$ in a refrigerator for $+\mathrm{P}$ and $-\mathrm{P}$ $4{ }^{\circ} \mathrm{C}$ treatment, with the same light conditions as in the growth room. The light intensity of both growth room and refrigerator was $100 \mu \mathrm{mol} \mathrm{m} \mathrm{m}^{-2} \mathrm{~s}^{-1}$. Samples were collected to perform further analyses.

For the dark treatment, seedlings were first kept at $23{ }^{\circ} \mathrm{C}$ in $+\mathrm{P}$ or $-\mathrm{P}$ media under the proper light intensity $\left(100 \mu \mathrm{mol} \mathrm{m}^{-2} \mathrm{~s}^{-1}\right)$ for three days. After normal and consistent germination, seedlings were treated with $23{ }^{\circ} \mathrm{C}$, $4{ }^{\circ} \mathrm{C}$, dark and light condition for another four days, respectively.

\section{RNA-seq library preparation}

Total RNA was extracted using roots of 7-day-old seedlings by Trizol method (Invitrogen Lige Technologies), with two biological replicates ( 100 pooled roots/replicate). After quality check, the preparation of RNA-Seq libraries was performed according to [16].

\section{Analysis of RNA-seq data}

Reads with primer/adaptor contamination, PHRED quality score lower than 20 , and those with ambiguous bases were removed. Filtered reads were mapped with TopHat2 (version 2.0.8) against Arabidopsis TAIR10 reference genome. Two mismatches were allowed for analyses with minimum intron length of 60nt and that of maximum was $6000 \mathrm{nt}$. Reads that aligned to rRNA or tRNA were removed. Cuffdiff2 mapping outputs were used to calculate expression counts of gene locus. Normalization was performed against RPKM by edgeR package [44]. Expression was considered significant with a cutoff value of 0.5 RPKM [45]. EdgeR was also used to determine differential expression, where $\mathrm{p}$-value $\leq 0.01$ and fold change $>2$ were criteria of significant change. Differentially expressed genes were clustered using all the detected transcripts or individual functional groups. After $\log _{2}$-transformation of all the ratio values, Cluster and Treeview programs were used to perform centroid linkage hierarchical clustering [46]. The raw data has been submitted, the accession number is PRJNA609588.

\section{Quantitative real-Time PCR analysis}

For quantitative real-time PCR (qPCR) analysis, total RNA was extracted from 7 days old seedlings using TIANGEN RNAprep pure plant kit (Tiangen Co., Beijing) according to previously reported method of [16]. The primer sequences used for detection of the mRNA expression of phosphate starvation induced and photosynthesis related genes are listed in Table S11.

\section{Fe histochemical staining assay}

Perls staining method was used to detect Fe in roots, mainly stains labile (non-heme) $\mathrm{Fe}^{3+}$, as described by [47]. Briefly, roots from 7-day-old seedlings were vacuum infiltrated with Perls staining solution having equal volumes of $4 \%(\mathrm{v} / \mathrm{v}) \mathrm{HCl}$ and $4 \%(\mathrm{w} / \mathrm{v})$ potassium ferrocyanide. After $15 \mathrm{~min}$ of infiltration, the samples were kept in the same solution at room temperature for another $30 \mathrm{~min}$. Thereafter samples were rinsed with ultrapure water to stop the reaction. HCG clearing solution with1 $\mathrm{g} / \mathrm{ml}$ chloral hydrate in $15 \%$ glycerol was used and finally cleared samples were examined with a DIC microscope. $D A B$ intensification was performed as described by [11].

\section{Fe content quantification in roots}

Root tissues were used to detect Fe content by bathophenanthrolinedisulfonic acid colorimetric assay as described by [48].

\section{Transmission electron microscopy of shoot apical meristems}

For transmission electron microscopy we used shoot apical meristems from 10-day-old seedlings. Seeds were kept in growth room at $23{ }^{\circ} \mathrm{C}$ for $16 / 8 \mathrm{~h}$ day night light conditions. Six days later, half of the seedlings were kept at $4{ }^{\circ} \mathrm{C}$ refrigerator with $+\mathrm{P}$ or $-\mathrm{P} 4{ }^{\circ} \mathrm{C}$ treatments, for four days. The second half of seedlings were kept at $+\mathrm{P}$ or -P $235{ }^{\circ} \mathrm{C}$. Samples were fixed in $2.5 \%$ glutaraldehyde for $24 \mathrm{~h}$ according to [16]. Stained shoot apical meristems were analyzed using the transmission electron microscope (H-7650B, Hitachi).

\section{Detection of Chlorophyll autofluorescence}

Chlorophyll autofluoescence was detected in roots of 10-day-old seedlings using confocal laser scanning microscope (LSM710; Carl Zeiss) at excitation wave length of $488 \mathrm{~nm}$.

\section{Accession numbers}

Sequence data from this article can be found in the TAIR database under the following accession numbers: ALMT1 (At1g08430), STOP1 (At1g34370), LPR1 (AT1G23010), LPR2 (AT1G71040), IPS1 (At3g09922), 
KIN1 (At5g15960), ERF109 (At4g34410), MAPKKK19 (At5g67080), PIN5 (At5g16530), COR15A (At2g42540), CBF2 (At4g25470), CBF3 (At4g25480), BBX28 (AT4G27310), BBX29 (At5g54470), BBX31 (At3g21890), RBCS (At5g38430), AGT1 (At2g13360), GOX1 (At3g14420), PSAH2 (At1g52230), HY2 (AT3G09150), FED A (At1g60950).

\section{Abbreviations}

Pi: phosphate; -P: phosphate starvation; PS: photosystem; QC: quiescent center; SCN: stem cell niche; almt1: aluminum activated malate transporter 1; stop 1: sensitive to proteinrhizotoxicity 1; ROS: reactive oxygen species; qPCR: quantitative real-timePCR .

\section{Supplementary Information}

The online version contains supplementary material available at https://doi. org/10.1186/s12870-021-03381-z.

Additional file 1: Figure S1. Relative phosphate starvation and chilling stressinduced gene expression (as determined by $\mathrm{qPCR}$ ) in 7-day-old seedlings of WTgrown on $+\mathrm{P}$ and $-\mathrm{P}$ media under $23^{\circ} \mathrm{C}$ and $4^{\circ} \mathrm{C}$. Values for each gene are relative to theexpression in $\mathrm{WT}$ on $+\mathrm{P} 23^{\circ} \mathrm{C}$, set at 1.0. Values are the means \pm SD of three biological replicates. An asterisk indicates a significant difference $(p<0.05, t$-test) from the WT.

Additional file 2: Table S1. Table of all mapped RNA reads.

Additional file 3: Table S2. Differentially expressed transcripts in $-P 23^{\circ} \mathrm{C}$ compared to $+\mathrm{P} 23^{\circ} \mathrm{C}$ plants.

Additional file 4: Table S3. Differentially expressed transcription factors in $-\mathrm{P} 23^{\circ} \mathrm{C}$ compared to $+\mathrm{P} 23^{\circ} \mathrm{C}$ plants.

Additional file 5: Table S4. Differentially expressed photosynthesis related genesin $-\mathrm{P} 23^{\circ} \mathrm{C}$ compared to $+\mathrm{P} 23^{\circ} \mathrm{C}$ plants.

Additional file 6: Table S5. Differentially expressed transcripts in $+\mathrm{P} 4^{\circ} \mathrm{C}$ compared to $+\mathrm{P} 23^{\circ} \mathrm{C}$ plants.

Additional file 7: Table S6. Differentially expressed transcription factors in $+\mathrm{P} 4^{\circ} \mathrm{C}$ compared to $+\mathrm{P} 23^{\circ} \mathrm{C}$ plants.

Additional file 8: Table S7. Differentially expressed photosynthesis related genesin $+\mathrm{P} 4^{\circ} \mathrm{C}$ compared to $+\mathrm{P} 23^{\circ} \mathrm{C}$ plants.

Additional file 9: Table S8. Differentially expressed transcripts in $-\mathrm{P} 4^{\circ} \mathrm{C}$ comparedto $-\mathrm{P} 23^{\circ} \mathrm{C}$ plants.

Additional file 10: Table S9. Differentially expressed transcription factors in $-\mathrm{P} 4^{\circ} \mathrm{C}$ compared to $-\mathrm{P} 23^{\circ} \mathrm{C}$ plants.

Additional file 11: Table S10. Differentially expressed photosynthesis related genesin $-\mathrm{P} 4^{\circ} \mathrm{C}$ compared to $-\mathrm{P} 23^{\circ} \mathrm{C}$ plants.

Additional file 12: Table S11. Sequences of the primers used for quantitative PCR.

\section{Acknowledgements}

We thank Prof. Dong Liu and Prof. Xiqing Ma for their valuable suggestions and constructive comments on the manuscript.

\section{Authors' contributions}

Jun Kang conceived the project; Xiaoning Gao, Jinsong Dong and Ayesha T. Tahir performed the experiments and analysis; Jun Kang and Ayesha T. Tahir wrote the paper. All authors read and approved the final manuscript.

\section{Funding}

This work was financially supported by the National Science Foundation of Tianjin (grant no. 16JCQNJC09800) and Hebei Provincial funding

\section{Availability of data and materials}

The materials of this study were provided by School of Life Sciences, Tianjin University. Correspondence and requests for materials should be addressed to Jun Kang (jun.kang@tju.edu.cn).

\section{Declarations}

Ethics approval and consent to participate

Not applicable.

\section{Consent for publication}

Not applicable.

\section{Competing interests}

All the authors declare that they have no competing interests.

\section{Author details}

${ }^{1}$ School of life sciences, Tianjin University, No.92 Weijin Road, Nankai District, 300072 Tianjin, China. ${ }^{2}$ Shanghai Center for Plant Stress Biology and Center of Excellence for Molecular Plant Sciences, Chinese Academy of Sciences, No. 3888 Chenhua Road, 201602 Shanghai, P. R. China. ${ }^{3}$ Department of Biosciences, COMSATS University Islamabad, Park road, 45550 Islamabad, Pakistan.

Received: 10 August 2021 Accepted: 29 November 2021

Published online: 11 January 2022

\section{References}

1. Kumari K, Samantaray S, Sahoo D, Tripathy BC: Nitrogen, phosphorus and high $\mathrm{CO}(2)$ modulate photosynthesis, biomass and lipid production in the green alga Chlorella vulgaris. Photosynthesis Research 2021, 148(1-2):17-32.

2. Rao IM, Terry N: Leaf Phosphate Status, Photosynthesis, and Carbon Partitioning in Sugar Beet (IV. Changes with Time Following Increased Supply of Phosphate to Low-Phosphate Plants). Plant Physiol 1995, 107(4):1313-1321.

3. Natr L: MINERAL NUTRIENTS - A UBIQUITOUS STRESS FACTOR FOR PHOTOSYNTHESIS. Photosynthetica 1992, 27(3):271-294.

4. Li L, Qiu X, Li X, Wang S, Zhang Q, Lian X:Transcriptomic analysis of rice responses to low phosphorus stress. Chinese Sci Bull 2010, 55(3):251-258.

5. Misson J, Raghothama KG, Jain A, Jouhet J, Block MA, Bligny R, Ortet P, Creff A, Somerville S, Rolland N et al: A genome-wide transcriptional analysis using Arabidopsis thaliana Affymetrix gene chips determined plant responses to phosphate deprivation. Proceed National Acad Sci USA 2005, 102(33):11934-11939.

6. Hu Z, Fan J, Xie Y, Amombo E, Liu A, Gitau MM, Khaldun ABM, Chen L, Fu J: Comparative photosynthetic and metabolic analyses reveal mechanism of improved cold stress tolerance in bermudagrass by exogenous melatonin. Plant Physiol Biochem 2016, 100:94-104.

7. Starck Z, Niemyska B, Bogdan J, Tawalbeh RNA: Response of tomato plants to chilling stress in association with nutrient or phosphorus starvation. Plant Soil 2000, 226(1):99-106.

8. Hegedus A, Janda T, Horvath GV, Dudits D: Accumulation of overproduced ferritin in the chloroplast provides protection against photoinhibition induced by low temperature in tobacco plants. J Plant Physiol 2008, 165(15):1647-1651.

9. Moenneloccoz P, Heathcote P, Maclachlan DJ, Berry MC, Davis IH, Evans MCW: PATH OF ELECTRON-TRANSFER IN PHOTOSYSTEM-1 - DIRECT EVIDENCE OF FORWARD ELECTRON-TRANSFER FROM A(1) TO FE-SX. Biochem 1994, 33(33):10037-10042.

10. Zheng Z, Wang Z, Wang X, Liu D: Blue Light-Triggered Chemical Reactions Underlie Phosphate Deficiency-Induced Inhibition of Root Elongation of Arabidopsis Seedlings Grown in Petri Dishes. Molecular Plant 2019, 12(11):1515-1523.

11. Dong J, Pineros MA, Li X, Yang H, Liu Y, Murphy AS, Kochian LV, Liu D: An Arabidopsis ABC Transporter Mediates Phosphate Deficiency-Induced Remodeling of Root Architecture by Modulating Iron Homeostasis in Roots. Molecular Plant 2017, 10(2):244-259. 
12. Mueller J, Toev T, Heisters M, Teller J, Moore KL, Hause G, Dinesh DC, Buerstenbinder K, Abel S: Iron-Dependent Callose Deposition Adjusts Root Meristem Maintenance to Phosphate Availability. Developmental Cell 2015, 33(2):216-230.

13. Ticconi CA, Lucero RD, Sakhonwasee S, Adamson AW, Creff A, Nussaume L, Desnos T, Abel S: ER-resident proteins PDR2 and LPR1 mediate the developmental response of root meristems to phosphate availability. Proceed National Acad Sci USA 2009, 106(33):14174-14179.

14. Balzergue C, Dartevelle T, Godon C, Laugier E, Meisrimler C, Teulon J-M, Creff A, Bissler M, Brouchoud C, Hagege A et al: Low phosphate activates STOP1-ALMT1 to rapidly inhibit root cell elongation. Nature Communications 2017,8.

15. Hoehenwarter W, Moenchgesang S, Neumann S, Majovsky P, Abel S, Mueller J: Comparative expression profiling reveals a role of the root apoplast in local phosphate response. Bmc Plant Biol 2016, 16.

16. Kang J, Yu H, Tian C, Zhou W, Li C, Jiao Y, Liu D: Suppression of Photosynthetic Gene Expression in Roots Is Required for Sustained Root Growth under Phosphate Deficiency. Plant Physiol 2014, 165(3):1156-1170.

17. Mudge SR, Rae AL, Diatloff E, Smith FW: Expression analysis suggests novel roles for members of the Pht 1 family of phosphate transporters in Arabidopsis. Plant J 2002, 31(3):341-353.

18. Zhu HF, Qian WQ, Lu XZ, Li DP, Liu X, Liu KF, Wang DW: Expression patterns of purple acid phosphatase genes in Arabidopsis organs and functional analysis of AtPAP23 predominantly transcribed in flower. Plant Molecular Biol 2005, 59(4):581-594.

19. Buhtz A, Pieritz J, Springer F, Kehr J: Phloem small RNAs, nutrient stress responses, and systemic mobility. Bmc Plant Biol 2010, 10.

20. Liu T-Y, Aung K, Tseng C-Y, Chang T-Y, Chen Y-S, Chiou T-J: Vacuolar Ca2+/ $\mathrm{H}+$ Transport Activity Is Required for Systemic Phosphate Homeostasis Involving Shoot-to-Root Signaling in Arabidopsis. Plant Physiol 2011, 156(3):1176-1189.

21. de Abreu-Neto JB, Turchetto-Zolet AC, Valter de Oliveira LF, Bodanese Zanettini MH, Margis-Pinheiro M: Heavy metal-associated isoprenylated plant protein (HIPP): characterization of a family of proteins exclusive to plants. Febs J 2013, 280(7):1604-1616.

22. Sirko A, Wawrzynska A, Rodriguez MC, Sektas P: The family of LSU-like proteins. Front Plant Science 2015, 5.

23. He Y, Chen B, Pang Q, Strul JM, Chen S: Functional specification of Arabidopsis isopropylmalate isomerases in glucosinolate and leucine biosynthesis. Plant Cell Physiol 2010, 51(9):1480-1487.

24. Redovnikovic IR, Textor S, Lisnic B, Gershenzon J: Expression pattern of the glucosinolate side chain biosynthetic genes MAM1 and MAM3 of Arabidopsis thaliana in different organs and developmental stages. Plant Physiol Biochem 2012, 53:77-83.

25. Schuster J, Knill T, Reichelt M, Gershenzon J, Binder S: BRANCHED-CHAIN AMINOTRANSFERASE4 is part of the chain elongation pathway in the biosynthesis of methionine-derived glucosinolates in Arabidopsis. Plant Cell 2006, 18(10):2664-2679.

26. Flis A, Mengin V, Ivakov AA, Mugford ST, Hubberten H-M, Encke B, Krohn N, Hoehne M, Feil R, Hoefgen R et al: Multiple circadian clock outputs regulate diel turnover of carbon and nitrogen reserves. Plant Cell Environment 2019, 42(2):549-573.

27. Salome PA, Weigel D, McClung CR: The Role of the Arabidopsis Morning Loop Components CCA1, LHY, PRR7, and PRR9 in Temperature Compensation. Plant Cell 2010, 22(11):3650-3661.

28. Ohta M, Sato A, Renhu N, Yamamoto T, Oka N, Zhu J-K, Tada Y, Suzaki T, Miura K: MYC-type transcription factors, MYC67 and MYC70, interact with ICE1 and negatively regulate cold tolerance in Arabidopsis. Scientific Reports 2018, 8 .

29. Lin F, Jiang Y, Li J, Yan T, Fan L, Liang J, Chen ZJ, Xu D, Deng XW: B-BOX DOMAIN PROTEIN28 Negatively Regulates Photomorphogenesis by Repressing the Activity of Transcription Factor HY5 and Undergoes COP1Mediated Degradation. Plant Cell 2018, 30(9):2006-2019.

30. Izumi M, Tsunoda H, Suzuki Y, Makino A, Ishida H: RBCS1A and RBCS3B, two major members within the Arabidopsis RBCS multigene family, function to yield sufficient Rubisco content for leaf photosynthetic capacity. J Experimental Botany 2012, 63(5):2159-2170.

31. Bernal M, Casero D, Singh V, Wilson GT, Grande A, Yang H, Dodani SC, Pellegrini M, Huijser P, Connolly EL et al: Transcriptome Sequencing Identifies SPL7-Regulated Copper Acquisition Genes FRO4/FRO5 and the
Copper Dependence of Iron Homeostasis in Arabidopsis. Plant Cell 2012, 24(2):738-761.

32. Ishihara S, Takabayashi A, Ido K, Endo T, Ifuku K, Sato F: Distinct functions for the two PsbP-like proteins PPL1 and PPL2 in the chloroplast thylakoid lumen of arabidopsis. Plant Physiol 2007, 145(3):668-679.

33. Liu J, Wang P, Liu B, Feng D, Zhang J, Su J, Zhang Y, Wang J-F, Wang H-B: A deficiency in chloroplastic ferredoxin 2 facilitates effective photosynthetic capacity during long-term high light acclimation in Arabidopsis thaliana. Plant J 2013, 76(5):861-874

34. Modde K, Timm S, Florian A, Michl K, Fernie AR, Bauwe H: High serine:glyoxylate aminotransferase activity lowers leaf daytime serine levels, inducing the phosphoserine pathway in Arabidopsis. J Experimental Botany 2017, 68(3):643-656.

35. Hopkins JA, Kiss JZ: Phototropism and gravitropism in transgenic lines of Arabidopsis altered in the phytochrome pathway. Physiologia Plantarum 2012, 145(3):461-473.

36. Majee M, Kumar S, Kathare PK, Wu S, Gingerich D, Nayak NR, Salaita L, Dinkins R, Martin K, Goodin M et al: KELCH F-BOX protein positively influences Arabidopsis seed germination by targeting PHYTOCHROMEINTERACTING FACTOR1. Proceed National Acad Sci USA 2018, 115(17):E4120-E4129.

37. Baek D, Jin Y, Jeong JC, Lee H-J, Moon H, Lee J, Shin D, Kang CH, Kim DH, Nam J et al: Suppression of reactive oxygen species by glyceraldehyde3-phosphate dehydrogenase. Phytochemistry 2008, 69(2):333-338.

38. Liu J, Yang H, Lu Q, Wen X, Chen F, Peng L, Zhang L, Lu C: PSBPDOMAIN PROTEIN1, a Nuclear-Encoded Thylakoid Lumenal Protein, Is Essential for Photosystem I Assembly in Arabidopsis. Plant Cell 2012, 24(12):4992-5006.

39. Tjus SE, Moller BL, Scheller HV: Photosystem I is an early target of photoinhibition in barley illuminated at chilling temperatures. Plant Physiol 1998, 116(2):755-764.

40. Cho S, Yu S-i, Park J, Mao Y, Zhu J-K, Yun D-J, Lee B-h: Accession-Dependent CBF Gene Deletion by CRISPR/Cas System in Arabidopsis. Front Plant Sci 2017,8.

41. Mikkelsen MD, Thomashow MF: A role for circadian evening elements in cold-regulated gene expression in Arabidopsis. Plant J 2009 60(2):328-339.

42. Zhai Q, Li C-B, Zheng W, Wu X, Zhao J, Zhou G, Jiang H, Sun J, Lou Y, Li $C$ : Phytochrome chromophore deficiency leads to overproduction of jasmonic acid and elevated expression of jasmonate-responsive genes in Arabidopsis. Plant Cell Physiol 2007, 48(7):1061-1071.

43. Takabayashi A, Niwata A, Tanaka A: Direct interaction with ACR11 is necessary for post-transcriptional control of GLU1-encoded ferredoxindependent glutamate synthase in leaves. Scientific Reports 2016, 6.

44. Robinson MD, McCarthy DJ, Smyth GK: edgeR: a Bioconductor package for differential expression analysis of digital gene expression data. Bioinformatics 2010, 26(1):139-140.

45. Jiao Y, Meyerowitz EM: Cell-type specific analysis of translating RNAs in developing flowers reveals new levels of control. Molecular Syst Biol 2010, 6.

46. Eisen MB, Spellman PT, Brown PO, Botstein D: Cluster analysis and display of genome-wide expression patterns. Proceed National Acad Sci USA 1998, 95(25):14863-14868.

47. Roschzttardtz H, Conejero G, Curie C, Mari S: Identification of the Endodermal Vacuole as the Iron Storage Compartment in the Arabidopsis Embryo. Plant Physiol 2009, 151(3):1329-1338.

48. Tamarit J, Irazusta V, Moreno-Cermeno A, Ros J: Colorimetric assay for the quantitation of iron in yeast. Analytical Biochemistry 2006, 351(1):149-151.

\section{Publisher's Note}

Springer Nature remains neutral with regard to jurisdictional claims in published maps and institutional affiliations. 